\title{
Interpreting Nursing Metatheory through Complexity Integration Nursing Theory: A Scoping Review
}

\section{Sharon L. Van Sell}

Professor, The Houston J. and Florence A. Doswell College of Nursing, Texas Woman's University, USA

\begin{abstract}
Aim: The aim of the scoping review for the interpreting nursing metatheory study was to determine the presence or absence of metatheory in the nursing literature, to interpret nursing metatheory, and to determine if the Complexity Integration Nursing Theory is the primary metatheory for unifying the profession of nursing.

Methods: Conducted a systematic interpretive scoping review using a modified Arksey and O'Malley framework involving 13 databases, gray literature, secondary sources of nursing theory textbooks, and six subjectively selected interdisciplinary metatheorieswith application to nursing published between 1987 and 2012 with nursing applications published within one year or up to 11 years. Evaluated identified nursing metatheories using the nine questions for interpreting nursing metatheory.

Results: The interpreting nursing metatheory study retrieved seven nursing metatheories through electronic database searches, nursing theory textbooks, interdisciplinary metatheories, and gray literature; that met inclusion criteria for using the nine questions of interpreting nursing metatheory. One nursing metatheory, the Complexity Integration Nursing Theory, met all nine questions and acknowledged all nursing theories past, present, and future, and focused on the individual nurse regardless of nursing practice domain; one nursing metatheory met eight, one met seven, one met six, one met four, and two met three out of nine questions.

Conclusion: The interpreting nursing metatheory scoping review provides an important high-level synthesis of nursing metatheory research, confirms the absence of nursing metatheory in primary and secondary nursing literature, and highlights the overall need for increased sophisticated methodological approaches to metatheory research in nursing especially with the trend towards interdisciplinary metatheory. The Complexity Integration Nursing Theory was the only nursing metatheory meeting all of the interpreting nursing metatheory questions and is the primary metatheory for unifying the profession of nursing.
\end{abstract}

\section{Introduction}

The development, application, and role of nursing theories characterize numerous scholarly debates, appear in primary and secondary sources of knowledge, and emerge as a never-ending stream of questions between scholars and practitioners. Agreement exists that nursing theory informs research, practice, and education. Nursing theories involve four levels of theoretical thinking known as nursing metatheory, grand nursing theory, middle-range nursing theory, and practice or situational nursing theories. Nursing metatheory, being the most abstract of the four levels of theoretical thinking, was very limited in the nursing literature. Nevertheless, determining if nursing metatheory is necessary for practice surfaced as a pressing nursing theory question [1].The purpose of this study was (a) to facilitate knowledge synthesis about nursing metatheory, (b) to conduct a comprehensive, systematic, interpretive scoping literature review utilizing the five-stage framework of Arksey and O'Malley and further enhanced by Levac et al., (c) to determine the presence or absence of metatheory in nursing, (d) to examine the extent, range and nature of metatheory in nursing, and (e) to summarize and disseminate the research findings related to nursing metatheory.

Historically, the nursing profession regarded nursing theory as a "set of concepts, definitions, and propositions that present a systematic view of various phenomena related to nursing's unique role; guides practice, education, and research" [2]. Whereas, Drs. Im and Meleis (1999) indicated that "theory means an organized, coherent, and systematic articulation of a set of statements related to significant questions in a discipline that are communicated in a meaningful whole to describe or explain phenomena or a set of phenomenon" [3, p. 11]. Even without an agreed unified definition of nursing theory, applying a nursing theory supports the development of a nursing identity, validates nursing, and expands understanding of the purpose and role of nurses in the healthcare setting $[4,5]$.The nursing theory provides a framework in which to view the world, assists in explaining and predicting nursing practice, and the base of nursing theory observes nursing phenomena representing many roles and purposes. Additionally, nursing theories significantly influence what the nursing profession knows and what the nursing profession needs to know.

Historically, the nursing profession regarded nursing theory as a "set of concepts, definitions, and propositions that present a systematic view of various phenomena related to nursing's unique role; guides practice, education, and research" [2]. Whereas, Drs. Im and Meleis (1999) indicated that "theory means an organized, coherent, and systematic articulation of a set of statements related to significant questions in a discipline that are communicated in a meaningful whole to describe or explain phenomena or a set of phenomenon" [3, p. 11].

"Corresponding Author: Prof. Sharon L. Van Sell, The Houston J. and Florence A. Doswell College of Nursing, 5500 Southwestern Medical Avenue, \#7209, Dallas, Texas, USA, 75235-7299, Tel: 1-864-275-3527, FAX: 214-689-6539; E-mail: svansell@twu.edu

Citation: Van Sell SL (2017) Interpreting Nursing Metatheory through Complexity Integration Nursing Theory: A Scoping Review. Int J Nurs Clin Pract 4: 235. doi: https://doi.org/10.15344/2394-4978/2017/235

Copyright: @ 2017 Van Sell. This is an open-access article distributed under the terms of the Creative Commons Attribution License, which permits unrestricted use, distribution, and reproduction in any medium, provided the original author and source are credited. 
Even without an agreed unified definition of nursing theory, applying a nursing theory supports the development of a nursing identity, validates nursing, and expands understanding of the purpose and role of nurses in the healthcare setting $[4,5]$.The nursing theory provides a framework in which to view the world, assists in explaining and predicting nursing practice, and the base of nursing theory observes nursing phenomena representing many roles and purposes. Additionally, nursing theories significantly influence what the nursing profession knows and what the nursing profession needs to know.

Professional nursing practice is based on theory even if the nurse is unable to identify the specific theoretical foundations to nursing practice. Reflect for a moment: accepted widely is hand hygiene as a universal standard signifying that nurses will wash their hands before and after providing nursing care. Most nurses acknowledge washing their hands before and after care, but they cannot identify the theory supporting hand hygiene. What theory supports hand washing? Louis Pasteur introduced the concept of the germ theory of disease, and Dr. Robert Koch proved the germ theory through his "postulates that still serve as a guide for determining if a microorganism is the cause of a disease" $[6, p .5]$. Additionally, in the nineteenth century even before the discovery of the germ theory of disease, Florence Nightingale promoted cleanliness with frequent hand washing using soap and water [7].

Nursing develops, utilizes, and labels many different types of theory by their nature and purpose. "Metatheory is global in nature and stipulates, in the broadest terms, the phenomena of interest to a discipline... [And] furnishes the concepts and propositions that are epistemological building blocks for disciplinary knowledge development" [8, p. 129]. Multiple definitions of metatheory emerged from the research literature, and like theory, no agreed unified definition of metatheory surfaced. The Merriam-Webster Dictionary (2016) definition for metatheory was "defined as a theory concerned with the investigation, analysis, or description of theory itself" [9].According to Walker and Avant (2011) "metatheory focused on philosophical and methodological questions related to the development of a theory base for nursing" [10, p. 6]. The Dictionary of Nursing Theory and Research (2010) indicated that "metatheory is a theory about theory; it is concerned with generating knowledge and debate within a discipline around broad issues, such as the nature of theory in general, the type of theory needed by the discipline, theory building processes, suitable criteria for analyzing and evaluating theory, and guidelines for theory use in practice" [11].Additionally, Dr. Steven E. Wallis, Director of the Foundation for the Advancement of Social Theory, conducted a literature search and identified over 20 definitions of metatheory. Dr. Wallis suggested the definition: "Metatheory is primarily the study of theory, including the development of overarching combinations of theory, as well as the development and application of theorems for analysis that reveals underlying assumptions about theory and theorizing" [12, p. 78].The diversity in defining metatheory was extensive across disciplines. Even though the nursing literature was very limited regarding nursing metatheory research articles, other disciplines such as sociology,philosophy, psychology, education, business, and computer science, to name a few, were abounding with research articles regarding metatheory.

Interestingly, the majority of nursing theory textbooks published in the United States of America may mention metatheory as a level of theoretical thinking, may or may not provide a definition nor include metatheory in the textbook index, and one textbook referred to a nursing metatheory entitled the Complexity Integration Nursing
Theory [13]. Seven out of 26 nursing theory textbooks (which are considered secondary sources) contained at least one example of a nursing metatheory, and 16 nursing theory textbooks did not contain metatheory in the index nor provide a definition of metatheory. Refer to Table 1(Supplementary File) for an analysis of the nursing theory textbooks for presence or absence of nursing metatheory.

The nursing professional recognized the underpinnings of the nursing discipline as theory, research, and practice, and cautioned that "the discipline of nursing is on a slippery slope with regard to the ever increasing lack of nursing theory in its work" [14]. "Are meta-theories in nursing necessary for practice?" was the question raised by Dr. Pamela N. Clarke who confirmed that "understanding the philosophical and scientific base of the discipline would ideally be required for both advanced practice and research" [1, p. 127]. However, where are the nursing practice meta-theories?

Nursing metatheories are a way of thinking centered on the nurse, define the relationship between nursing variables, and provide focus. For example, nursing metatheories integrate the relation of the nursing variables identified in the nursing metaparadigm as the concepts of person, environment, health, and nursing [15-16], which enables key areas for focus in nursing research and nursing practice. Additionally, nursing metatheories delineate the functions and characteristics of constructs targeted for study by nurse researchers as well as prescribing an understanding and the function of professional nursing. Therefore, nursing metatheories define vital nursing constructs (including the nursing metaparadigm), focus on the nurse, facilitate a perspective of the interactions within the nursing profession, develop overarching combinations of theory, account for all nursing theory, past, present and future, guide nursing research goals and methodologies, and contribute to a nursing focus.

\section{Methods}

\section{Background}

During the past 18 years, nurse researchers utilized and grew the scoping review methodology [21-26]. The scoping review methodology emerged as an alternative to the traditional literature review and systematic reviews because scoping reviews required less time and fewer resources [27]. Fawcett understood selecting a methodology to delineate all literature about a broad topic, and to identify gaps in the reported research without conducting a critical evaluation of the research was most appropriate for scoping reviews [28]. Moher, Stewart, and Shekelle (2015) agreed and emphasized: "the scoping review, when what is needed is not detailed answers to specific questions but rather an overview of a broad field" [29]. Nurse researchers, as well as numerous other disciplines' researchers, utilized scoping reviewsfor synthesizing research evidence and as a form of knowledge synthesis even though no agreed-upon unifying scoping review terminology, definition, definitive procedure, or purposeexist [30-37]. However, the methodological steps outlined in the Arksey and O'Malley [17] framework published in 2005 and further enhanced by Levac et al. [18] in 2010 are the most cited protocol for conducting scoping reviews across disciplines [20-21].

The Joanna Briggs Institute (JBI) published the Joanna Briggs Institute Reviewers' Manual 2015, a methodology for JBI Scoping Reviews based on the Arksey and O'Malley framework with enhancement by Levac, Colquhoun, and O'Brien, and the Joanna Briggs Institute methods of evidence synthesis [19]. A requirement 
of the JBI Scoping Review is an a-priori protocol with inclusion and exclusion criteria that relate clearly to the objective and review question, which is "based upon the PCC (Population, Concept and Context) elements of the inclusion criteria" [19, p. 7].The JBI Scoping Review methodology focused on five stages, incorporated both quantitative and qualitative research, clarified research questions, identified relevant studies using a three step literature search, carefully selected studies, extracted and charted data in a tabular and narrative format, and collated the study results to identify implications for policy, practice or research [24, p. 120]. Only time will tell if the JBI Scoping Review methodology becomes the methodology of choice for nursing scoping reviews.

The scoping review methodology was evaluated and chosen for conducting this interpreting nursing metatheory study. The study's scoping review process started by forming a collaboration with Eula M. Oliphant, MLA, Manager Health Science Library at Texas Woman's University (TWU). The collaboration maximized expertise in evidence-based nursing best practice research searches and synthesis, to clarify the board research question, and to facilitate identification of search terms with a selection of searchable databases.Institutional Review Board (IRB) approval was not required because the utilization of secondary (existing) data sets does not meet the definitional criteria for "human subjects" research.

The aim of the scoping review for the interpreting nursing metatheory study was to determine the presence or absence of metatheory in the nursing literature, to interpret nursing metatheory, and to determine if the Complexity Integration Nursing Theory is the primary metatheory for unifying the profession of nursing. The scoping review methodology utilized the framework outlined by Arksey and O'Malley (2005) and enhanced by Levac et al. [17-18]. The five-step application of the scoping review framework consisted of an iterative process: (a) identifying the research question, (b) identifying relevant studies, (c) study selection, (d) charting the data, (e) collating, summarizing and reporting the results, and (f) an optional consultation exercise, which was not implemented [17-18]. The scoping review method focused on achieving in-depth and broad results as well as identification of all relevant literature regardless of research design. Arksey and O"Malley indicated that: “The process is not linear but iterative, requiring researchers to engage with each stage in a reflexive way and, where necessary, to repeat steps to ensure that the literature is covered in a comprehensive way" [17, p. 22].

\section{The Research Question and Interpreting Nursing Metatheory}

The research question guiding the scoping review was 'What are the characteristics and range of nursing metatheories documented in the primary and secondary sources of nursing literature? For the purpose of the interpreting nursing metatheory study, the definition of scoping review was "A scoping review or scoping study is a form of knowledge synthesis that addresses an exploratory research question aimed at mapping key concepts, types of evidence, and gaps in research related to a defined area or field by systematically searching, selecting, and synthesizing existing knowledge" [20, p. 1291].Additionally, for the interpreting nursing metatheory study, the definition of metatheory was "defined as a theory concerned with the investigation, analysis, or description of theory itself" [9]. As previously discussed,nursingmetatheories are a way of thinking. For the selected nursing scoping review articles, interpreting the nursing metatheory involved nine questions, including:
1. Does the article identify a nursing metatheory?

2. Does the individual nursingmetatheory define vital nursing constructs (including the nursing metaparadigm)?

3. Does theindividual nursing metatheory focus on the nurse?

4. Does the individual nursing metatheory apply to all domains of nursing?

5. Does the individual nursing metatheory facilitatea perspective of the interactions within the nursing profession?

6. Does the individual nursing metatheory develop overarching combinations of theory?

7. Does the individual nursing metatheory acknowledge all nursing theory, the past, present, and future?

8. Does the individual nursing metatheory facilitate guiding nursing research goals and methodologies?

9. Does theindividual nursing metatheorycontribute to a nursing focus?

A secondary category of the nursing scoping review occurred regarding interdisciplinarymetatheories with application to nursing. Selected subjectively were six interdisciplinary metatheories with application to nursing for acknowledgment in the study.

\section{Data Sources and Search Strategy}

A comprehensive search strategy was developed to identify primary studies (published and unpublished)by searching for nursing research evidence to identify the presence or absence and characteristics of nursing metatheories. Conducting the scoping review search occurred between May and November2016, usingthe Texas Woman's University Health Sciences Library. The scoping literature searchassimilateda formal electronic search of 13 subject-relevant research databases. Thereference list of all retrieved articles was 'hand-searched'plus key nursing journals, applicable organizations, and conferences, as well as gray literature, selected secondary sources, and search engines.The electronic search of 13 databases encompassed: Academic Search Complete, CINAHL Complete, Cochrane Library, EBSCOHOST, Health Sciences: A Sage Full-Text Collection, Joanna Briggs Institute EBP Database, OVID, Nursing Collection (Journal at Ovid Full Text), Medline with Full Text (EBSCO), ProQuest Nursing and Allied Health Database, PubMed Remote, Science Direct, and Scopus.Evaluation of secondary sources consisted of 26 nursing theory textbooks regarding the inclusion of metatheory in the index, a definition of metatheory, the mention of metatheory in the text, and the presence of a nursing metatheory example. Excluded from the nursing theory textbook evaluation were primary nursing theory books supporting grand, middle-range, or practice theory as well as conceptual models. A search conducted with the Google Scholar search engine identified relevant nursing metatheory documents or reports published from conference or seminar programs. Additionally, conducted Google and Chrome searches for gray literature (i.e. difficult to locate or unpublished material) as well as websites of nursing organizations supporting nursing theory, such as the American Holistic Nursing Association or the American Association of Critical Care Nurses. The scoping review search was limited to English-languagearticles. However, the search strategy was not limited to study design or year.

\section{Inclusion and Exclusion Criteria}

The inclusion criteria for the interpreting nursing metatheory study were: primary nursing research articles without date restriction 
that identified the presence of a nursing metatheory, or provided information regarding the characteristics of a nursing metatheory. All study designs were eligible for inclusion. Inclusion criteria reported nursing research frameworks utilizing a nursing metatheory (including published conference abstracts). Included for further evaluation were research articles discussing theories with an unclear or a changing level of theoretical thinking. Also, inclusion occurred through subjective appraisals for relevance, which allowed inclusion of articles key to explaining relevant metatheories that might be missed but were deemed sufficiently relevant such as metatheory from secondary literature in nursing theory textbooks or primary literature of an original nursing theory book. Additionally, a new area emerged representing interdisciplinary metatheory with application to nursing. Therefore, results provide subjectively selected examples of six interdisciplinary metatheories with applications to nursing.

Excluded were primary nursing research articles not written in the English language, dissertations, or if the focus was nursing theory not identified as a nursing metatheory. Therefore, the scoping review excluded grand nursing theory, middle range nursing theory, practice nursing theory;nursing conceptual models, andnursing metaparadigm as well as metatheory not specific to nursing, but concentrated on psychology, sociology, business, computer science, or education.Also, articles excluded if nursing metatheory not discussed at all, or if judged (subjectively) that the theoretical discussion was cursory, for example where an existing theory was briefly referred to or implied as part of a general discussion.

\section{Search Terms}

Comprehensive database searches required multiple search terms including nursing metatheory, metatheory in nursing, metatheory, nursing meta-theory, meta-theory in nursing, and meta-theory. Also, the term metatheory in nursing mapped to ten subheadings including nursing theory; philosophy, nursing; education, nursing, baccalaureate; teaching; models, nursing; nurse-patient relations; nursing; research; logic; metatheory in nursing search as a keyword. Search term testing validated that the search terms located primary nursing research articles consistent with the inclusion criteria before conducting a comprehensive search encompassing the entire search strategy.

\section{Search Process}

The search process applied a two-stage screening method to assess the relevance of primary nursing research articles. Eligible inclusion articles identified the presence of a nursing metatheory, characterized a nursing metatheory, or described the utilization of a nursing metatheory as a framework for a nursing research study. Excluded were primary nursing research articles not published in English or not identifying a nursing metatheory. Evidence was from multiple sources sought through hand searching of references for information about a specific nursing metatheory.

The first stage of screening reviewed only the title and abstract of citations and identified citations for second stage full-text review. Subsequently, obtained all relevant citations deemed appropriate for full-text article review through the Texas Woman's University Health Sciences Library or inter-library loan. The full-text review excluded primary nursing research articles not meeting the inclusion criteria. Additionally, conducted individual literature searches using the identified nursing metatheory name and author to identify primary nursing research articles regarding specific nursing metatheories not previously identified but meeting inclusion criteria.

\section{Results}

\section{Scoping Review Search and Selection}

Appling the scoping review search strategy, the initial search conducted in May 2016 yielded 284,633 potentially relevant citations. The first stage screening review removed duplications, completed relevance screening, and identified 99articles meeting the inclusion criteria based on title and abstract, which facilitated the acquisition of full-text articles required for second stage review. The second stage of screening review evaluated the entire text, and 55research articles met the inclusion criteria and remained in the interpreting nursing metatheory study.

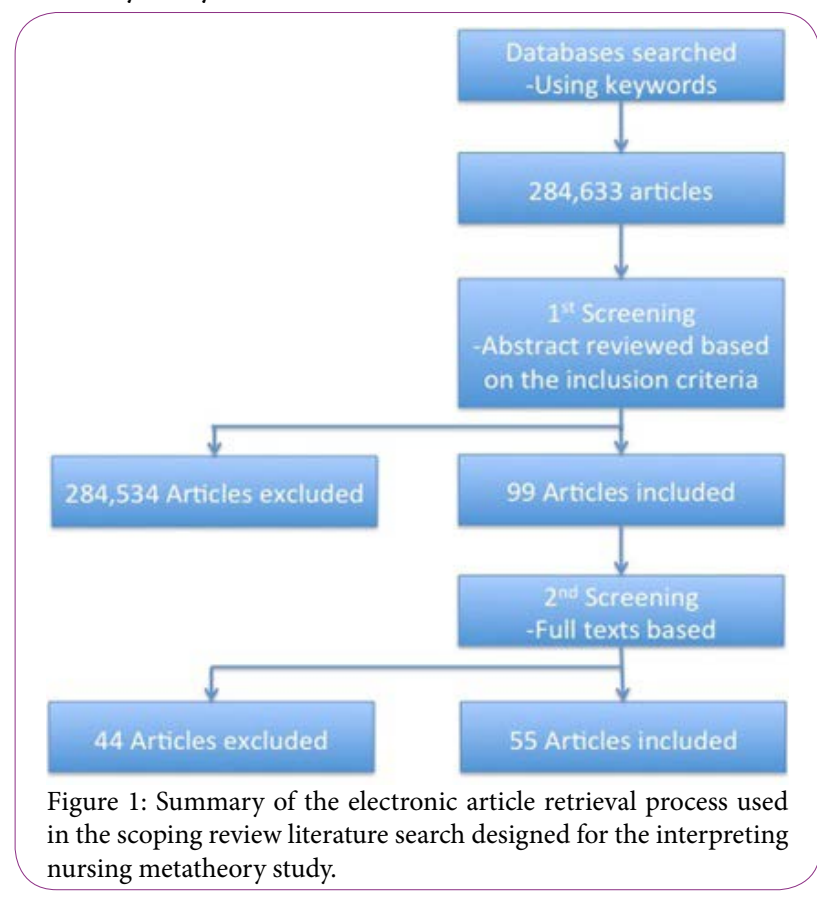

Numerous citations, totaling 284,534 articles, were excluded during the first stage of screening at the title and abstract level for failure to mention or discuss nursing metatheory. The term "metatheoretical thinking" appeared as a description of a thinking process used by the nursingtheorist. However, no nursing metatheory provided. In the nursing literature, one nurse "is an internationally recognized authority on nursing meta-theory, specializing in analysis and evaluation of conceptual models of nursing and nursing theories and the relationship between theory and research" [38, p. 238]. Dr. Jacqueline Fawcett, the nursing metatheoriststated, "Metatheorists study the nature and structure of knowledge" [38, p. 238]. Even so, the article did not present nor discuss a nursing metatheory, and no nursing metatheory emerged from the nursing literature authored by Dr. Fawcett. However, Dr. Fawcett facilitated the development of the nursing paradigm, authored multiple nursing theory textbooks, and serves as the editor of the Journal of Advanced Nursing.

In addition to the articles identified through the electronic databases scoping review, articles identified from other sources including secondary sources from nursing theory textbooks, Google searches, and hand analysis of references for identification of 42 additional articles. The total number of documents included in the Interpreting Metatheory Study was 97. 


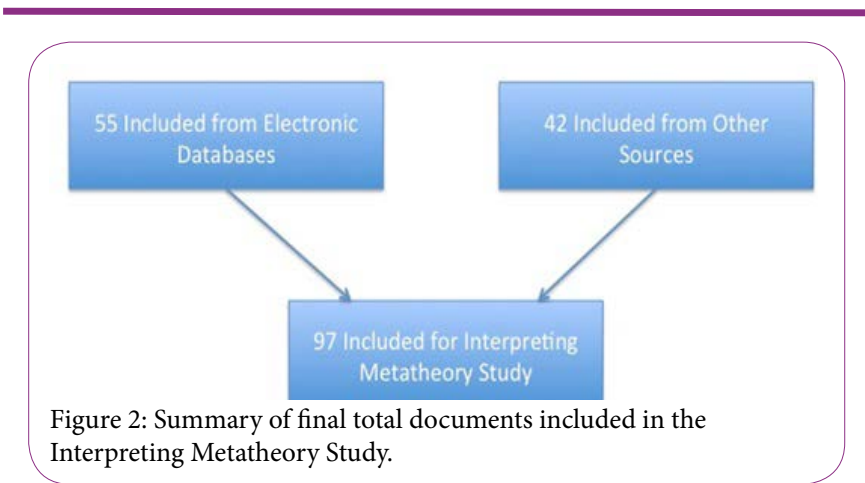

During the scoping review, a very limited number of nursing metatheories were identified when compared with a significant number of metatheories from other disciplines. Wondering where are the nursing metatheories led to a search of thesecondary literature (i.e. nursing theory textbooks) for identification of nursing metatheories. Table 1 evaluation of Metatheory in 26 Nursing Theory Textbooks Frequently Required for Nursing Courses in the United States of America for a summary of which nursing theory textbooks indexed metatheory, defined metatheory, mentioned metatheory and the author of metatheory in the text or provided an example of a nursing metatheory.

The four nursing metatheories identified from the secondary literature search of nursing theory textbooks were the Tidal Model, the Complexity Integration Nursing Theory, the Humanistic Nursing Theory, and the Relational Caring Complexity Theory. A copy of The Tidal Model e-book wasavailable following a request to the authors through the Tidal Model website at www.tidal-model.com.[39].The Complexity Integration Nursing Theory was an e-book entitled The Evolving Essence of the Science of Nursing: The Complexity Integration Nursing Theory [40] and listedin the CINAHL Complete database, or available through open access on Texas Woman's University Library home page by initiating a Catalogue Search with the e-book title (retrieved from http://www.twu.edu/library/). Two editions of the Humanistic Nursing Theory book, with different publishers,emerged. For a free download of the Humanistic Nursing Theory book go to http://www.gutenberg.org/files/25020/25020-8.txt [41]. A primary textbook source, Nursing, Caring, and Complexity Science: For Human Environment Well-Being [42], containing the relational caring complexity theory, surfaced during the evaluation of nursing theory textbooks and, was therefore includedin Table 1 and Table 2(Supplementary File). A Google search yielded four articles with three articles from the proceedings of national conferences, which provided the complex synergistic system, a theoretical model incorporating complexity, synergy, and general systems into one theory [43-44], and the fourth article from a website was the MetaTheory of Transcendence[44].Hand searching of the article references resulted in the retrieval of four additional articles. Refer to Table 2 for a listing of nursing metatheories meeting inclusion criteria and with supporting articles. Recognizing the trend toward interdisciplinary participation in research and patient-centered outcomes resulted in thesubjective selection of six interdisciplinary metatheories with application to nursing for inclusion in the study; refer to Table 3 (Supplementary File) for a listing of interdisciplinary metatheories with application to nursing.

The article by von Krogh, Dale, and Naden reported choosing "Kim's (2000) metatheory of nursing as the analyzing tool because she claimed her theory could be used to identify and examine phenomena within the domain of nursing" [45, p. 277]. However, further evaluation revealed that Kim provided a nursing typology to systematize nursing knowledge and did not refer to her work as a metatheory. Nor were any other references identifying Kim's work as a metatheory located [46]. Therefore, excluded Kim's The Nature of Theoretical Thinking in Nursing from the interpreting nursing metatheory study [46].

Two philosophy professors, Dickoff and James, known for working with nurses for more than 20 years published "A Theory of Theories: A Position Paper" in Nursing Research in 1968 [47]. Also, the collaboration of Dickoff and James with Wiedenbach resulted in the publication of "Practice Oriented Theory Part I and II" published in Nursing Research in 1968 [48-49]. Even though the work was recognized as discussing theories for nursing, and described in numerous nursing publications, the publications did not meet the inclusion criteria for consideration in the interpreting nursing metatheory study.

To summarize, a total of 85 electronic database primary articles met the inclusion criteria. Also, six primary source books, two metatheories from search engines, two articles from hand searching, and six interdisciplinary metatheory categoriesplus application to nursingarticles, thus representing a total of 42 relevant documents met the inclusion criteria for the interpreting metatheory study. Therefore, a total of 97 documents met the inclusion criteria for the interpreting metatheory study with supporting articles. Refer to Table 2 for a listing of the 55 articles meeting the inclusion criteria for nursing metatheory with supporting articles. Refer to Table 3 for a listing of the six interdisciplinary metatheory categories plus application to nursing articles for a total of 42 relevant documents.

The emphasis on interdisciplinary collaboration led to metatheories incorporating multiple disciplines, and frequently interdisciplinary metatheory with specific application to nursing emerged during the scoping review of the nursing literature. Therefore, six interdisciplinary metatheories were subjectively selected as well as the nursing application of the interdisciplinary metatheory. Refer to Table 3 for a summary listing of the interdisciplinary metatheories with application to nursing. The interdisciplinary metatheories focused on integral theory, complex synergistic systems incorporating complexity science, synergy, and general systems, resilience and resiliency, realist metatheory related to gender in mental health, postpartum depression, and disability research; evolutionary systems theory as a unifying meta-theory of psychological science, and Kuyper's Social Work Metatheory. The interdisciplinary metatheory may be applied in nursing without clarification as a borrowed metatheory, for example, resilience as a power within for oncology patients even though historically nursing has utilized the resilience concept in multiple formats. The evolutionary psychology as a metatheory for the social sciences focused on how to gather interdisciplinary evidence for a psychological adaptation and mentioned medical and nursing science, however, no indication of medical or nursing participation in development or application of the evolutionary psychology as a metatheory occurred[51-52].Another example was the utilization of Kuyper's Social Work Metatheory as aguide for development and application of multiple nursing theories, even though Kuyper's metatheory was not completely developed or available in the nursing literature. Analyses of the interdisciplinary metatheories with nursing application indicated articles did not necessarily identify a nursing metatheory per se. Additionally, frequently the nursing metaparadigm constructs were not clarified; the interdisciplinary metatheories were 
very specific and did not apply to all domains of nursing; overarching combinations of theory did not occur, and the nursing metatheory did not differentiate all nursing theory, the past, present, and future.

\section{Analysis of Interpreting Nursing Metatheory}

For the selected scoping review nursing metatheory articles, interpreting the nursing metatheory involved an analysis consisting of nine interpreting nursing metatheory questions. The nine questions focused on determining if the individual nursing metatheory (1) identified as a nursing metatheory, (2) defined vital nursing constructs including the nursing metaparadigm; (3) focus on the nurse; (4) applied to all domains of nursing; (5) facilitated a perspective of interactions within the nursing profession; (6) developed overarching combinations of nursing theory; (7) acknowledged all nursing theory, the past, present, and future; (8) facilitated guiding nursing research goals and methodologies; and (9) contributed to a nursing focus. Refer to the summary of the results of the analysis of the interpreting nursing metatheory in Table 4 (Supplementary File).

\section{Analysis of Interpreting Nursing Metatheory According to Nine Questions}

The oldest nursing metatheory was Sredl's Nursing Aerohemodynamics Metatheory originally published 1983, which developed fromobservation of every aspect of the flight environment and interrelates the dynamics of physiology with stressors endemic within the flight environment [61, 62]. The Nursing Aerohemodynamics Metatheory met three of the nine interpreting nursing metatheory questions and two questions met with limited application. The theory was comprehensive but limited to flight nursing with a focus on aerohemodynamics of the patient. Currently, the nursing aerohemodynamics metatheory may in actuality be a practice theory for flight nursing.

The Humanistic Nursing Metatheory by Paterson \& Zderad in 1988 represents a distinguished and highly recognized nursing metatheory [41]. The authors identified Humanistic Nursing as both a metatheory and a conceptual framework focused on the nurse-patient relationship analyzed as a human-to-human event rather than a nurse-to-patient interaction. The Humanistic Nursing Metatheory met six of the nine questions and defined vital nursing constructs. The metatheory published when the nursing metaparadigm was in the beginning stages of acceptance by the nursing profession. Therefore, the authors did not define the nursing metaparadigm components, nor account for nursing theories past, present, and future.

The metatheory by Ray and Turkel, Theory of Relational Caring Complexity, in 2000-2001, evoked the complexity of nursing practice situation and focused on nursing practice, complexity science, and the bureaucratic caring theory. The Ray and Turkel regarded"the caring relationship as the complexity in nursing science" with multidisciplinary focus and "spiritual-ethical caring at the center of complex relational caring practice of nursing in healthcare organizations" [42, p. 114]. The Relational Caring Complexity theory met eight of the nine questions but did not acknowledge nursing theories from the past, present, or future.

The Tidal Modal by Barker and Buchanan-Barker in 2001 identified as a metatheory by the authors, however, in a nursing textbook, Tidal Model was reclassified as a high-level mid-range theory [57, p. 231]. Widely received internationally, the Tidal Modal focused on psychiatric and mental health nursing. The Tidal Model is specific to psychiatric and mental health nursing. Thereforeit did not meet five of the nine interpreting nursing metatheory questions.

The Complexity Integration Nursing Theory (CINT) by Van Sell and Kalofissudis in 2002 focused on the individual nurse's synthesis and integration of human being nursing theory, social equality nursing theory, the theory of nursing knowledge, and theory of nursing practice [40].The CINT met each of the nine interpreting nursing metatheory questions. Additionally, the CINT applied as a research theoretical framework by Binner, Ross, and Browner, which proved the research-practice gap as individual nurses' knowledge deficit [58]. The CINT acknowledges all nursing theories, the past, present, and future. The individual nurse has absolute autonomy to determine what she does or does not do in her nursing practice, the individual nurse is knowledgeable about all nursing theories, the past, present, and future, and is encouraged to choose all or part of any nursing theory that will facilitate the best outcomes. Theoretically, the other metatheories are available to the nurse applying CINT to nursing practice. The CINT as a metatheory in nursing is accomplished at organizing and integrating a variety of research areas involving factors such as the human being, the social equality, nursing knowledge, and nursing practice, as well as the nursing metaparadigm components of person, environment, health, and nursing. The CINT as a metatheory is like a safety net to the practicing nurse and can unify the profession of nursing. Therefore, CINT is the primary metatheory for unifying the profession of nursing.

Wilkin's Metatheory of Transcendence from 2002 had a foundation based on Jung Psychology with an emphasis on patient-nurse communication as well as the integration of the disciplines of nursing and psychology and exhibiting a multidisciplinary relevance. The Metatheory of Transcendence is an evolving theory and did not meet four of the interpreting metatheory questions, as well as two questions, had limited application.

Jarrin's Integral Philosophy and Definition of Nursing: Nursing Metatheory from 2006-2007, was informed by the Integral Theory from Dr. Ken Wilber, derived to nursing, and evolvedinto the Integrality of Situated Caring in Nursing and the Environment theory [60]. The Integral Philosophy and Definition of Nursing metatheory met seven of the interpreting metatheory questions. However,the theory did not acknowledge nursing theories, the past, present, and future, and had limited contribution to the nursing focus question. A challenge to Jarrin's metatheory classification relates to Dossey's Theory of Integral Nursing from 2008, which also was informed by Wilber's Integral Theory,but classified as a grand nursing theory instead of a metatheory [59]. The two theories have many similarities and differences. However, Dossey's theory is widely accepted and practiced by the holistic nursing community. Jarrin's theory appears to be continuing to evolve.

\section{Discussion}

The Interpreting Nursing Metatheory Study presented several challenges related to the identification of nursing metatheory. The scoping review identified few nursing metatheories. Wanting to clarify the situation regarding a limited number of nursing metatheories retrieved from the scoping review, when associated disciplines such as philosophy, sociology, computer science, psychology, and business were bounding with metatheories, led to the evaluation of nursing theory textbooks regarding the presence or absence of nursing metatheory. Evaluation of 26 nursing theory textbooks identified 
Citation: Van Sell SL (2017) Interpreting Nursing Metatheory through Complexity Integration Nursing Theory: A Scoping Review. Int J Nurs Clin Pract 4: 235. doi: https://doi.org/10.15344/2394-4978/2017/235

Page 7 of 8

six nursing metatheories. Additionally, 16 out of 26 nursing theory textbooks did not index metatheory nor provide detailed discussion with examples of nursing metatheories. Even though metatheory is identified as the most abstract level of theory, some nursing theory textbooks do not contain nursing metatheory information. In nursing theory textbooks the emphasis converted from four levels of theory to nursing metaparadigm and conceptual models, even though agreement exist that conceptual models do not lead to nursing theories. Nurses' recognized nursing theory authors such as Chinn \& Kramer, Fawcett, Reed, and Parse emphasized nursing metaparadigm with an absence of nursing metatheory. Interesting to note, not only is metatheory excluded from many nursing theory textbooks, but nursing metatheories were very limited in the nursing literature. Jacqueline Fawcett, identified as a nursing metatheorist and distinguished nursing leader regarding nursing metaparadigm, is also the editor of the Journal of Advanced Nursing. Chin, author of multiple nursing textbooks, is the editor of Advances in Nursing Science. Reed developed the mid-range theory of self-transcendence, is author of a nursing theory textbook, and is the editor of Applied Nursing Research. Parse is developed the human becoming theory, a grand nursing theory, is a nursing theory textbook author, andis editor of Nursing Science Quarterly. One has to argue that perhaps the absence of nursing metatheory is directly related to the nursing theory textbookauthors' exclusion of nursing metatheory as well as exclusion of nursing metatheories by editors of nursing journals.

The presence of nursing metatheory in primary and secondary nursing literature is very limited. The current trend appears to be moving toward interdisciplinary metatheory with application to nursing. However, the process is uncertain for deriving interdisciplinary metatheory into nursing. For example, Ken Wilber's Integral Metatheory was derived as a grand nursing theory by Dr. Barbara Montgomery Dossey as the Theory of Integral Nursing However, Dr. Olga F. Jarrin derived a nursing metatheory from Ken Wilber's Integral Metatheory.

Historically, the nursing leaders encouraged the nursing metaparadigm and conceptual models while nursing metatheory declined as associated disciplines embraced metatheory. Nursing theorists and nursing researchers need increased sophisticated methodological approaches to metatheory research in nursing and to establish interdisciplinary collaboration focused on the process, evaluation, and application for deriving interdisciplinary metatheories into nursing practice. The nurse theorist and the nurse researcher need to be present during the development of interdisciplinary metatheories with application to nursing practice. In addition, the nurse theorist and the nurse researcher are ideal professionals to provide the leadership for collaboration during the advancement of interdisciplinary metatheories.

\section{Conclusion}

The interpreting nursing metatheory scoping review provides an important high-level synthesis of nursing metatheory research. In particular, the interpreting nursing metatheory study confirms the absence of nursing metatheory introduced in primary and secondary nursing literature since 2008, and highlights the overall need for increased sophisticated methodological approaches to metatheory research in nursing especially with the trend towards interdisciplinary metatheory. The interpreting nursing metatheory study retrieved seven nursing metatheories meeting inclusion criteria for interpretation. The Complexity Integration Nursing Theory was the only nursing metatheory meeting all of the interpreting nursing metatheory questions and, therefore is the primary metatheory for unifying the profession of nursing.

\section{Competing Interests}

The author declares she is co-author of The Evolving Essence of the Science of Nursing: The Complexity Integration Nursing Theory.

\section{Funding}

This article was published with support from Texas Woman's University Libraries' Open Access Fund.

\section{References}

1. Clarke PN (2015) Meta-theory in nursing: Necessary for practice? Nurs Sci Q 28: $127-128$

2. Nursing theory (2012) Medical Dictionary for the Health Professions and Nursing, Farlex.

3. Im EO, Meleis Al (1999) Situation-Specific theories: Philosophical roots, properties, and approach. ANS Adv Nurs Sci 22: 11-24.

4. Colley C (2003) Nursing Theory: Its importance to practice. Nursing Standard 17: 33-37.

5. Marañón AA, Pera MPI (2015) Theory and practice in the construction of professional identity in nursing students: A qualitative study. Nurse Educ Today 35: 859-863.

6. Gaynes R (2011) Germ Theory: Medical Pioneers in Infectious Diseases (1). Washington, DC: ASM Press. Accessed October 22, 2016, from ProQuest ebrary.Electronic reproduction. Palo Alto, Calif.: ebrary, 2011.

7. Nightingale, F (1820-1910) Notes on nursing: What it is, and what it is not. London: Harrison, 59, Pall Mall, Bookseller to the Queen, [1883].

8. Lasiuk GC, Ferguson LM (2005) From Practice to Midrange Theory and Back Again: Beck's Theory of Postpartum Depression. ANS Adv Nurs Sci 28: $127-136$

9. "Metatheory" (2016) In Merriam-Webster Online Dictionary.

10. Walker LO, Avant KC (2011) Strategies for Theory Construction in Nursing. Boston, MA: Prentice Hall, an imprint of Pearson.

11. Powers BA, Knapp T (2010) In A. Powers, Dictionary of Nursing Theory and Research. New York: Springer Publishing Company.

12. Wallis S (2010) Toward a Science of Metatheory. Integral Review 6: 73120

13. Sitzman K, Eichelberger LW (2017) Understanding the work of nurse theorist: A creative beginning. Burlington, MA: Jones \& Bartlett Learning.

14. Karnick PM (2014) A case for nursing theory in practice. Nurs Sci Q 27: 117.

15. Fawcett $\mathrm{J}$ (1984) The metaparadigm of nursing: Present status and future refinements. Image 16: 84-87.

16. Fawcett J (1996) On the Requirements for a Metaparadigm: An Invitation to Dialogue. Nurs Sci Q 9: 94-97.

17. Arksey H, O'Malley L (2005) Scoping studies: Towards a methodological framework. International Journal of Social Research Methodology 8: 1932.

18. Levac D, Colquhoun H, O'Brien (2010) Scoping studies: Advancing the methodology. Implementation Science 5: 69.

19. Joanna Briggs Institute (2015) Joanna Briggs Institute Reviewers' Manual: Methodology for JBI Scoping Reviews. Adelaide, South Australia: The Joanna Briggs Institute.

20. Colquhoun HL, Levac D, O'Brien KK, Straus S, Tricco AC, et al. (2014) Scoping reviews: Time for clarity in definition, methods, and reporting. J Clin Epidemiol 67: 1291-1294.

21. Cacchione PZ (2016) The Evolving Methodology of Scoping Reviews (editorial). Clin Nurs Res 25: 115-119. 
Citation: Van Sell SL (2017) Interpreting Nursing Metatheory through Complexity Integration Nursing Theory: A Scoping Review. Int J Nurs Clin Pract 4: 235. doi: https://doi.org/10.15344/2394-4978/2017/235

Page 8 of 8

22. Davis K, Drey N, Gould D (2009) What are scoping studies? A review of the nursing literature. International Journal of Nursing Studies 46: 1386-1400.

23. Kable AK, Pich J, Maslin-Prothero SE (2012) A structured approach to documenting a search strategy for publication: A 12 step guideline for authors. Nurse Educ Today 32: 878-886.

24. Khalil H, Pharm M, Pharm B, Peters M, Godfrey CM, et al. (2016) An evidence-based approach to scoping reviews. Worldviews on Evid Based Nurs 13: 118-123.

25. Peterson J, Pearce PF, Ferguson LA, Langford CA (2016) Understanding scoping reviews: Definition, purpose, and process. J Am Assoc Nurse Pract 5: 1-5.

26. Sarrami-Foroushani P, Travaglia J, Debono D, Clay-Williams R, Braithwaite $J$ (2015) Scoping meta-review: Introducing a new methodology. Clin Trans Sci 8: $77-81$

27. Anderson S, Allen P, Peckham S, Goodwin N (2008) Asking the right questions: Scoping studies in the commissioning of research on the organization and delivery of health services. Health Res Policy Syst 6: 7.

28. Fawcett J (2013) Thoughts about conceptual models, theories, and literature reviews. Nurs Scie Q 26: 285-288.

29. Moher D, Stewart L, Shekelle P (2015) All in the family: Systematic reviews, rapid reviews, scoping reviews, realist reviews and more. Syst Rev 4: 183-184.

30. Straus SE, Kastner M, Soobiah C, Antony J, Tricco AC (2016) Introduction: Engaging researchers on developing, using, and improving knowledge synthesis methods: a series of articles describing the results of a scoping review on emerging knowledge synthesis methods. J Clin Epidemiology 73: $15-18$

31. Tricco AC, Antony J, Soobiah C, Kastner M, Cogo E, et al. (2016) Knowledge synthesis methods for generating or refining theory: a scoping review reveals that little guidance is available. J Clin Epidemiol 73: 36-42.

32. Tricco AC, Lillie E, Zarin W, O'Brien K, Colquhoun H, et al. (2016) A scoping review on the conduct and reporting of scoping reviews. BMC Medical Research Methodology 16: 15

33. Tricco AC, Soobiah C, Antony J, Cogo E, MacDonald H, et al. (2016) A scoping review identifies multiple emerging knowledge synthesis methods, but few studies operationalize the method. J Clin Epidemiol 73: 19-28.

34. Pham MT, Rajic A, Greig JD, Sargeant JM, Papadopoulos A, et al. (2014) A scoping review of scoping reviews: advancing the approach and enhancing the consistency. Res Synth Methods 5: 371-385.

35. Gough D, Thomas J, Oliver S (2012) Clarifying differences between review designs and methods. Systematic Reviews 1: 28.

36. Kastner M, Tricco AC, Soobiah C, Lillie E, Perrier L, et al. (2012) What is the most appropriate knowledge synthesis method to conduct a review? Protocol for a scoping review. BMC Medical Research Methodology 12 114.

37. Rumrill PD, Fitzgerald SM, Merchant WR (2010) Using scoping literature reviews as a means of understanding and interpreting existing literature. Work 35: 399-404.

38. Clarke PN, Fawcett J (2013) Life as a Nurse Metatheorist. Nurs Sci Q 26 238-240.

39. Barker P, Buchanan-Barker P (2007) The Tidal Model: Mental Health, Reclamation, and Recovery.

40. Van Sell SL, Kalofissudis IA (2002) The Evolving Essence of the Science of Nursing: The Complexity Integration Nursing Theory. Chania, Crete Greece.

41. Paterson JG, Zderad LT (2008) Humanistic Nursing. Project Gutenberg eBook,

42. Davidson A, Ray M, Turkel M (2011) Nursing, Caring, and Complexity Science: For Human Environment Well-Being. New York: Springer Publishers.
43. Burroughs J (2013) Understanding Nursing Through a Theoretical Model: Complexity, Synergy, and General Systems. Proceeding of the National Conference on Undergraduate Research (NCUR) 2013, University of Wisconsin, La Cross, WI.

44. Wilkins LE (2002) The Meta-Theory of Transcendence.

45. Von Krogh G, Dale C, Naden D (2005) A framework for integrating NANDA $\mathrm{NIC}$, and NOC terminology in electronic patient records. J Nurs Scholarsh 37: $275-281$

46. Kim HS (2000) The Nature of Theoretical Thinking in Nursing. (2nd edition) New York: Springer.

47. Dickoff J, James P (1968) A theory of theories: A position paper. Nurs Res 17: 197-203.

48. Dickoff J, James P, Wiedenbach E (1968) Theory in a practice discipline: Part I, Practice oriented theory. Nurs Res 17: 415-435.

49. Dickoff J, James P, Wiedenbach E (1968) Theory in a practice discipline: Part II, Practice oriented research. Nursing Research 17: 545-554.

50. Constantino RE, Crane PA (2013) Theoretical and conceptual frameworks and models for understanding forensic nursing. In Constantino RE, Crane PA, \& Young SE (Eds) Forensic nursing: Evidence-based principles and practice. Philadelphia: F.A. Davis Company.

51. Badcock PB (2012) Evolutionary systems theory: A unifying meta-theory of psychological science. Review of General Psychology16: 10-23.

52. Ploeger A, Hoort BV (2015) Evolutionary psychology as a metatheory for the social sciences: How to gather interdisciplinary evidence for a psychological adaptation. Review of General Psychology19: 381-392.

53. Humanistic Nursing Theory (2017) The Free Dictionary

54. Ray MA, Turkel MC (2012) A transtheoretical Evolution of Caring Science within Complex Systems. International Journal for Human Caring 16: 2839.

55. Kineman JJ (2008) Fundamental of relational caring complexity. In: Allen J Wilby $\mathrm{J}$ (eds) Proceedings of the 52nd annual meeting of the International Society for the System Sciences, Toronto, 2008.

56. Barker P (2001) The Tidal Model: Developing a Person-Centered Approach to Psychiatric and Mental Health Nursing. Perspect Psychiatr Care 37: 7987.

57. McEwen M, Wills E (2011) Theoretical basis for nursing (1st ed.) Philadelphia: Wolters Kluwer/Lippincott Williams \& Wilkins.

58. Binner M, Ross D, Browner I (2011) Chemotherapy-Induced Peripheral Neuropathy: Assessment of Oncology Nurses' Knowledge and Practice. Oncol Nurs Forum 38: 448-454.

59. Dossey BM (2008) Theory of integral nursing. Advances in Nursing Science 31: E52-73.

60. Jarrin O (2012) The Integrality of Situated Caring in Nursing and the Environment. ANS Adv Nurs Sci 35: 14-24.

61. Sredl D (1983) Airborne Patient Care Management: A Multidisciplinary Approach. St. Louis: Medical Research Associates Publications.

62. Sredl D (2008) Conceptual model: The aerohemodynamics metatheory. Teaching \& Learning in Nursing 3: 115-120. 